\title{
DEBATE EN TORNO AL ACUERDO EXTRAJUDICIAL DE PAGOS: ¿UNA VERDADERA MEDIACIÓN CONCURSAL?
}

\author{
Almudena VAliño Ces \\ Profesora de Derecho Procesal \\ almudena.valino@usc.es \\ Universidad de Santiago de Compostela \\ CRistina Alonso SAlgado \\ Investigadora del Área de Derecho Procesal \\ cristina.alonso@usc.es \\ Universidad de Santiago de Compostela
}

\begin{abstract}
Resumen:
La introducción de la mediación en el marco del Derecho concursal es una medida audaz, pero no carente de riesgo. A través de la Ley de emprendedores y de la modificación llevada a cabo por el Real Decreto-Ley 1/2015, de 27 de febrero, el legislador dio un primer paso creando la figura del acuerdo extrajudicial de pagos, competencia del mediador concursal.

El régimen jurídico de esta institución preconcursal, que tiene por finalidad conseguir un acuerdo entre deudor y acreedores que evite el concurso, está siendo muy discutido, pues presenta diversas diferencias con la mediación tradicional, lo que lleva a la doctrina a negarle tal carácter.

A lo largo de este trabajo nos proponemos estudiar en detalle esta institución y la forma en que se regula, para concluir si merece o no la calificación de "mediación", así como el tímido avance que la creación de esta figura implica para el ordenamiento jurídico español.
\end{abstract}

Palabras clave: Acuerdo extrajudicial de pagos, acreedores, concurso consecutivo, Ley Concursal, mediación, mediación concursal, mediador, Plan de Pagos.

\begin{abstract}
:
The introduction of mediation in the context of the bankruptcy law is a bold but not lacking measure of risk. Through the law of entrepreneurs and modification carried out by the Royal Decree-Law 1/2015, of 27 February, the legislator gave a first step creating the figure of the settlement of payments, insolvency mediator competence.

The legal regime of the pre-insolvency institution, which aims to achieve an agreement between debtor and creditors that prevents the competition, is still very discussed, as it presents several differences with the traditional mediation, which leads to the doctrine to deny you such character.

Throughout this work, we study in detail this institution and the way in which is regulated, to conclude whether it is or not the qualification of "mediation", as well as the timid advance involving the creation of this figure to the Spanish legal order.
\end{abstract}

REJIE Nueva época: Revista Jurídica de Investigación e Innovación Educativa Núm.18, Junio 2018, pp. 119-132 
Keywords: Settlement of payments, creditors, consecutive contest, insolvency law, mediation, bankruptcy mediation, mediator, payment Plan.

Sumario: 1. Introducción. 2. Un binomio a debate: ámbito concursal y procedimiento mediador. 2.1. La Ley 14/2013 y el RDL 1/2015 como operadores de la modificación de la Ley Concursal. 2.2. Acuerdo extrajudicial de pagos. 2.3. Procedimiento de consecución del acuerdo extrajudicial de pagos. 3. Conclusión. Bibliografía.

\section{Introducción.}

En el actual contexto de crisis económica, la realidad ha evidenciado la incapacidad de la primigenia Ley 22/2003, de 9 de julio, Ley concursal ${ }^{1}$, toda vez que, concebida en un momento de prosperidad económica y reducido número de concursos, como es sabido, resultó más que insuficiente para abordar las consecuencias del nuevo escenario socioeconómico. La señalada Ley contaba con importantes lagunas y adolecía de no pocas disfunciones en la regulación del procedimiento. En buena lógica, las reformas legislativas no tardaron en llegar².

Con la LC, la preconcursalidad se limitaba a dos ámbitos de alcance incompleto. Por un lado, se circunscribía al relativo a los acuerdos personales extrajudiciales -amparados en la autonomía de la voluntad- que el deudor pudiera celebrar con algunos de sus acreedores, tratando de pactar la espera o la renuncia a acudir a la vía concursal; y, por otro, al ámbito societario en el que efectivamente existían reglas para el tratamiento de situaciones de desequilibrio entre el capital y el patrimonio, que conducían a la reducción del capital o, directamente, a la disolución de la sociedad en casos de pérdidas calificadas, abriéndose un procedimiento de liquidación que no evitaba el tránsito al procedimiento concursal.

Ante las referidas insuficiencias de la LC, la literatura especializada se dividió entre aquellos que consideraban que las reformas debían ser puntuales y aquellos otros que, en atención a las graves carencias de la Ley, entendían que sus líneas esenciales debían ser replanteadas ${ }^{3}$.

En particular, frente a la fijación en la LC de un procedimiento judicial único al que reconducir todas las posibles situaciones de insolvencia del deudor, se destacó la necesidad de regular de forma completa "[...] un procedimiento concursal o preconcursal alternativo de carácter parcialmente extrajudicial que permita solucionar

\footnotetext{
${ }^{1}$ En adelante, $\mathrm{LC}$.

${ }^{2}$ GómeZ SEgAdE, J. A. (2011), "Reflexión sobre la crisis económica y el derecho mercantil (referencia a los acuerdos de refinanciación en el concurso)", en Piloñeta Alonso, L. M. e IRIBARREn Blanco, M. (Coords.): Estudios de derecho mercantil en homenaje al profesor José María Muñoz Planas, Cizur Menor (Navarra): Civitas Thomson, pp. 351 y siguientes.

3 QuiJano González, J., "Las sucesivas reformas de la Ley Concursal española en materia de preconcursalidad", p. 3. [En línea] http://cuadernosdederechoparaingenieros.com/articulo/el-acuerdoextrajudicial-de-pagos/.
} 
de una manera ágil, flexible y económica muchas de las situaciones de crisis económica de los empresarios" ${ }^{4}$.

Así pues, con el objeto de dotar de viabilidad y continuidad a empresas en dificultades, y como método alternativo a la solución concursal, mediante el Real Decreto-Ley $3 / 2009$, de 27 de marzo, de medidas urgentes en materia tributaria, financiera y concursal, se llevó a cabo una primera reforma en profundidad de la LC, a través de la que se incorporó el denominado "período de espera", así como una Disposición adicional primera relativa a los acuerdos de refinanciación".

Con todo, en tanto que con la reforma no se obtuvieron los resultados deseados, la Ley 38/2011, de 10 de octubre, de reforma de la LC incorporó la regulación del concurso de personas físicas, dejando la puerta abierta a la posibilidad de adopción de medidas de solución extrajudiciales, incluida la mediación ${ }^{6}$. Aun cuando, como es sabido, el legislador ya había efectuado un llamamiento a contemplar "[...] opciones de solución extrajudicial", fue la Ley 5/2012, de 6 de julio, de mediación en asuntos civiles y mercantiles ${ }^{7}$, la que acabó por introducir la mediación en la materia ${ }^{8}$.

\footnotetext{
${ }^{4}$ Vid. la segunda de las conclusiones del I Congreso Español de Derecho de la Insolvencia, celebrado en Gijón del 16 al 18 de abril de 2009. [En línea] http://aedin.es/cedin-i-14.html.

${ }^{5}$ Esta Disposición adicional -"Escrituras públicas de formalización de acuerdos de refinanciación"señala: "Para el cálculo de los honorarios notariales de la escritura pública de formalización de los acuerdos de refinanciación a que se refiere la disposición adicional cuarta de la Ley 22/2003, de 9 de julio, Concursal, se aplicarán los aranceles correspondientes a los «Documentos sin cuantía» previstos en el número 1 del Real Decreto 1426/1989, de 17 de noviembre, por el que se aprueba el arancel de los Notarios. Los folios de matriz de la escritura y de las primeras copias que se expidan no devengaran cantidad alguna a partir del décimo folio inclusive".

${ }^{6}$ En el ámbito europeo se ha mantenido desde hace tiempo un interés por impulsar y promover los métodos y procedimientos no judiciales ni jurisdiccionales, id est, las ADR, a fin de asegurar un mejor acceso a la Justicia, como parte de la política de la Unión Europea dirigida a determinar un espacio de libertad, seguridad y justicia. Se produce, pues, una expansión de estas alternativas, en concreto de la mediación, en la mayor parte de los países. Ésta aparece como una institución que, en la actualidad, se erige como una pieza esencial del modelo de Justicia del siglo XXI, toda vez que constituye un procedimiento que posibilita gestionar el conflicto surgido, en algunas ocasiones evitándolo y en otras, solventando las diferencias planteadas entre las partes, ya sea total o parcialmente. VALIÑO CES, A. (2017), "La sesión informativa en la mediación intrajudicial ¿voluntaria u obligatoria?", en CASTILLEJO Manzanares, R. (Dir.), Alonso SAlgado, C. y Valiño Ces, A. (Coords.): La mediación a examen: experiencias innovadoras y pluralidad de enfoques, Santiago de Compostela: Servicio de Publicaciones e Intercambio Científico, p. 195.

Según el artículo 1 LM: "Se entiende por mediación aquel medio de solución de controversias, cualquiera que sea su denominación, en que dos o más partes intentan voluntariamente alcanzar por sí mismas un acuerdo con la intervención de un mediador". De esta definición se infiere que se trata de un método de solución de controversias. Y es que precisamente, con el propósito de dispensar un tratamiento integral del conflicto surge la mediación en el campo del Derecho. Se presenta como un auxiliar de la Justicia para intentar dar una mejor y más apta respuesta a determinados litigios, muy especialmente a aquellos en los que las partes implicadas requieren mantener una relación posterior a la resolución del conflicto concreto, utilizando para ello una metodología del diálogo y entendimiento de la postura de la parte contraria. CASTILLEJO MANZANARES. R. (2017), "La mediación", en CASTILlEJO MANZANARES, R. (Dir.), Noya FERREIRO, L. y RodRíguez Álvarez, A. (Coords.): Tratado sobre la disposición del proceso civil, Valencia: Tirant lo Blanch, p. 502.

${ }^{7}$ En adelante, LM. Esta Ley lleva a cabo una ordenación general de la mediación en el ámbito del Derecho privado y en el marco de las directrices comunitarias, establecidas en la Directiva 2008/52/CE del Parlamento Europeo y del Consejo, de 21 de mayo de 2008, sobre ciertos aspectos de la mediación en asuntos civiles y mercantiles.
} 
Sin embargo, no fue hasta la aprobación de la Ley 14/2013, de 27 de septiembre, de apoyo a los emprendedores y a su internacionalización, cuando se introdujo, a través de la incorporación a la LC de un nuevo Título X -denominado "El acuerdo extrajudicial de pagos"-, una alternativa que no cuenta con precedentes en nuestro ordenamiento jurídico, a pesar de la existencia de iniciativas legislativas favorables a los acuerdos extrajudiciales y de que un amplio sector doctrinal ya venía apostando por la potenciación de los "convenios extrajudiciales preconcursales".

Asimismo, cabe destacar que el reciente Real Decreto-Ley 1/2015, de 27 de febrero, de mecanismo de segunda oportunidad, reducción de la carga financiera y otras medidas de orden social $^{10}$, reforma en profundidad el régimen de exoneración del pasivo insatisfecho en el concurso y del acuerdo extrajudicial de pagos, especialmente respecto de la persona natural no empresario. Ésta tiene a su disposición una modalidad simplificada del expediente y un acceso más sencillo a la liberación de las deudas, ya que no se vincula a la satisfacción de un importe mínimo de su pasivo ${ }^{11}$.

\section{Un binomio a debate: ámbito concursal y procedimiento mediador.}

\subsection{La Ley 14/2013 y el RDL 1/2015 como operadores de la modificación de la Ley Concursal.}

Más allá de lo evidente respecto al concurso, el actual contexto socioeconómico demanda que se le ofrezca al empresario otras vías eficaces de solución, un proceso extrajudicial para el deudor insolvente, en el que intervenga un tercero neutral que aproxime a las partes con la finalidad de prevenir el tan temido estigma social, así como de evitar la liquidación de la empresa.

En la línea apuntada, la Ley 14/2013 introduce la figura del mediador concursal, justamente para poner a disposición de los empresarios un mecanismo alternativo al concurso de acreedores basado en la mediación, a través de la incorporación de ese

\footnotetext{
${ }^{8}$ Para profundizar sobre este tema, véase: CASTILlejo MANZANARES, R. (2013), Comentarios a la Ley 5/2012, de mediación en asuntos civiles y mercantiles, Valencia: Tirant lo Blanch y BARONA VILAR, S. (2013), Mediación en asuntos civiles y mercantiles en España. Tras la aprobación de la Ley 5/2012, de 6 de julio, Valencia: Tirant lo Blanch.

${ }^{9}$ ROJO FERNÁNDEZ-RIO, A. (2003), "La reforma del derecho concursal español”, en RoJO FERNÁNDEZRIO, A. (Dir.): La reforma de la legislación concursal, Madrid-Barcelona: Marcial Pons, pp. 107 y siguientes.

${ }^{10}$ En adelante, RDL 1/2015. Esta norma, grosso modo, contempla, entre otras cuestiones, medidas urgentes para la reducción de la carga financiera, que principalmente introduce una amplia modificación de la LC, del Real Decreto-Ley 6/2012, de 9 de marzo, de medidas urgentes de protección de deudores hipotecarios sin recursos y de la Ley 1/2013, de 14 de mayo, de medidas para reforzar la protección a los deudores hipotecarios, reestructuración de deuda y alquiler social.

${ }^{11}$ Para el caso del acuerdo extrajudicial de pagos de personas naturales no empresarios, existen dos especialidades. Por un lado, la competencia de estos acuerdos le corresponde al notario del domicilio del deudor, ante el cual se deberá presentar la solicitud y tramitar el expediente, salvo que se estimara conveniente la designación de un mediador concursal. Por otro, se acortan los plazos para la propuesta de acuerdo y convocatoria de los acreedores y se limita el posible contenido de la propuesta de acuerdo sólo a las opciones contenidas en las letras a), b) y c) del artículo 236.1 LC. Además, se limita el plazo de suspensión de las ejecuciones a un período de dos meses y, en este supuesto, el concurso consecutivo se abrirá directamente en la fase de liquidación.
} 
"acuerdo extrajudicial de pagos"12. Con todo, en el momento de aprobación de la Ley 14/2013 el alcance de esta segunda oportunidad era limitado, toda vez que únicamente podían acceder un determinado tipo de deudores ${ }^{13}$.

Con la aprobación del RDL 1/2015, la regulación sufrió ciertos cambios, y a pesar de que son muchos los que consideran que la reforma llega "[...] con retraso, cuando ya quedaron arruinadas y enterradas familias, autónomos y pequeñas empresas" $" 14$, lo cierto es que ha supuesto un salto cualitativo en absoluto desdeñable. Y ello porque ofrece un instrumento para que muchos particulares y autónomos no teman tener una deuda perpetua hasta su pago íntegro, respondiendo con su patrimonio presente y futuro, y se proteja definitivamente a sus familias y a los consumidores, concediendo la segunda oportunidad en el plano concursal a los deudores de buena fe que tengan deudas, cargas o gravámenes.

Aun cuando la reducción de las prohibiciones para poder acceder al acuerdo extrajudicial de pagos puede ser valorada de forma positiva, para PULGAR EZQUERRA ${ }^{15}$ la referida ampliación puede resultar cuestionable en tanto que la vía determinada es única para personas físicas y jurídicas, a pesar de que las finalidades perseguidas son distintas: poder acudir al mecanismo "exoneratorio" del artículo 178 bis LC, en el caso de las personas naturales y refinanciar o reestructurar su deuda, en el de las personas jurídicas.

\subsection{Acuerdo extrajudicial de pagos.}

A través del acuerdo extrajudicial de pagos, la Ley 14/2013 regula un nuevo mecanismo preconcursal de tratamiento de la insolvencia guiado por la figura del mediador concursal $^{16}$.

\footnotetext{
${ }^{12}$ A este respecto, su Exposición de Motivos prevé que "En la situación económica actual, son precisos tanto cambios en la cultura empresarial como normativos, con el objeto de garantizar que el fracaso no cause un empobrecimiento y una frustración tales que inhiban al empresario de comenzar un nuevo proyecto y pase a ser un medio para aprender y progresar".

${ }^{13}$ Asimismo, se regula por primera vez en nuestro país, el fresh start o segunda oportunidad, la cual se concreta en la posibilidad de que el deudor persona natural pueda cancelar de forma definitiva aquellas deudas que no pudo satisfacer con sus bienes presentes. Fue, precisamente, con ocasión do recrudecimiento de la recesión económica, el sobreendeudamiento hipotecario y la cuestión prejudicial planteada por el Juzgado de lo Mercantil núm. 3 de Barcelona al Tribunal de Justicia de la Unión Europea, cuando este tema empezó a ser objeto de atención en nuestro Derecho (caso Aziz en relación con la abusividad de ciertas cláusulas contractuales en el marco hipotecario).

${ }^{14}$ Martín Molina, P. B. (2015), "La segunda oportunidad para la persona natural, el autónomo y la pequeña empresa en el ámbito de la insolvencia”, Diario La Ley, Sección Doctrina, núm. 8531, 4 de mayo, Ref. D-172: p. 15.

${ }^{15}$ Pulgar EzQuerra, J. (2015), “Acuerdos extrajudiciales de pagos, PYMES y mecanismos de segunda oportunidad”, Diario La Ley, Sección Doctrina, núm. 8538, 13 de mayo, Ref. D-188: p. 8.

${ }^{16}$ El mediador, según la doctrina, no es más que "la persona u órgano que facilita el acuerdo, asiste a las partes para acercarlas, crea un ambiente propicio para su comunicación y asegura que las partes actúan con igualdad de armas, en igualdad de condiciones, reequilibrando si fuera necesario". PASTOR SELLER, E. (2013), "La mediación como herramienta de intervención social”, en GORJón GóMEZ, F. y LÓPEZ PelÁzez, A. (Coord.): Estado del arte de la mediación, Cizur Menor (Navarra): Editorial Aranzadi, p. 111.
} 
La intervención del mediador concursal tiene por finalidad facilitar la tramitación de un concurso en la búsqueda del cumplimiento por parte del deudor con sus acreedores. Por lo tanto, a él le corresponde el uso de estrategias comunicativas, cooperativas y negociadoras que, además de permitirle identificar las posiciones e intereses de las partes, le ayuden a las mismas a lograr una solución mutuamente aceptada y satisfactoria para todos ${ }^{17}$.

Ahora bien, esta figura suscita una importante controversia, pues se pone en tela de juicio la naturaleza del cargo de mediador concursal, así como del procedimiento, dado que se aparta de alguna de las notas características de la mediación ${ }^{18}$. El hecho de que el mediador sea nombrado, no por las propias partes en conflicto, sino por un Registrador Mercantil o notario, así como su posible conversión en administrador concursal en el eventual concurso consecutivo que pueda abrirse, son circunstancias que llevaron a una parte importante de la doctrina a negar que se trate de una auténtica mediación ${ }^{19}$.

Habida cuenta de lo expuesto, el objetivo del legislador no es otro que el de introducir ciertos ajustes en el procedimiento concursal con la finalidad de lograr que se evite a través de la mediación, esto es, por medio de un acuerdo tutelado entre deudor y acreedores, la declaración de concurso de algunas personas físicas y entidades mercantiles.

El procedimiento para conseguir este acuerdo -artículos 231 a 242 LC- tiene carácter extrajudicial y facultativo. Conjuntamente con los denominados acuerdos de refinanciación, el acuerdo extrajudicial de pagos comparte la consideración de "instituto preconcursal" ${ }^{20}$, toda vez que constituye una alternativa al concurso de acreedores,

\footnotetext{
${ }^{17}$ LASHERAS, P. (2014), “¿Es mediador el mediador concursal?”, Actualidad Jurídica Aranzadi, núm. 895, Editorial Aranzadi, Madrid: p. 1.

${ }^{18}$ La mediación concursal ha sido definida como "la intervención de un profesional especializado en materia concursal a la que la ley le atribuye unas funciones concretas, entre las que sobresale elaborar un plan de pagos, y cuyas actuaciones deben ser desarrolladas en la forma, en los tiempos y con los límites y condicionamientos que marca la ley". Boldó RoDA, C. (2015), "Capítulo XIV. El acuerdo extrajudicial de pagos. Aspectos procedimentales", en Boldó RodA, C. (Dir.) y Andreu Martí, M. M. (Coord.): La mediación en asuntos mercantiles, Valencia: Tirant lo Blanch, p. 394.

${ }^{19}$ Cfr. AgÜERo ORTIZ, A. (2013), "El mediador concursal como administrador extraconcursal", Revista de Derecho Concursal y Paraconcursal, núm. 20, Editorial La Ley, Sección Varia, segundo semestre: p. 286; MERINO ESPINAR, M. B. (2015), "Una primera aproximación a la realidad del acuerdo extrajudicial de pagos y la figura del mediador concursal y su relación con el Registro de la Propiedad", Revista de Derecho Civil, vol. II, núm. 1, enero-marzo: p. 181; vid. PUlGar EzQuerRA, J. (2013), "Ley de emprendedores y segunda oportunidad", El Notario del Siglo XXI, Opinión, núm. 51, septiembre-octubre. [En línea] http://www.elnotario.es/index.php/opinion/opinion/3517-ley-de-emprendedores-y-segundaoportunidad; SENÉS Motilla, C. (2014), "El acuerdo extrajudicial de pagos: ¿alternativa efectiva al concurso de acreedores?", Revista de Derecho Civil, vol. I, núm. 1, enero-marzo: p. 58.

${ }^{20}$ El prefijo "pre-“ antepuesto a concurso no sólo se refiere en este caso al período de tiempo que precede a su declaración, sino a aquél en el que un deudor en dificultades económicas aún no ha sido declarado en concurso. De manera que se utiliza para delimitar el período temporal en el que el deudor trata de evitar su concurso, a través de actuaciones "preconcursales". En cualquier caso, la alusión al concurso se fundamenta en la importancia que esos actos tendrán en el supuesto de una eventual futura declaración de concurso. Cuando se celebra uno de esos actos -por ejemplo, un acuerdo de refinanciación-, aún no se sabe si el deudor será declarado en concurso en el futuro, pero se contemplan las consecuencias que, dado el supuesto, se derivarían para el acto en cuestión. Por tal motivo, la expresión literal alcanza tanto el período que precede a la declaración de concurso, como aquél en que ésta se prevé y tiende a evitar.
} 
siendo por consiguiente incompatible con la admisión a trámite de la solicitud de concurso, ya sea necesario o voluntario. El procedimiento extrajudicial tampoco resulta compatible con el inicio de un proceso de negociación para la consecución de un acuerdo de refinanciación, precisamente, por perseguir ambas figuras objetivos antagónicos: la superación de la insolvencia, en el caso de los acuerdos de refinanciación, y la flexibilización de los pagos causados como consecuencia de la misma, en lo referente al acuerdo extrajudicial de pagos ${ }^{21}$.

Así las cosas, cabe destacar que inicialmente no todo deudor podía instar la negociación de un acuerdo extrajudicial de pagos. Antes de la reforma operada por el RDL 1/2015 sólo podían iniciar este mecanismo negociador los sujetos referidos en los apartados $1 \mathrm{y}$ 2 del artículo 231 LC. Ello no obstante, tras la señalada reforma, puede acogerse a este acuerdo extrajudicial cualquier persona física, sin que tenga que concurrir en ella la condición de empresario natural. En otras palabras, puede acceder a este acuerdo cualquier persona, física o jurídica, comerciante o no, que se encuentre en una situación de insolvencia actual o inminente ${ }^{22}$.

Por otro lado, la insolvencia del deudor se alza como el eje central del procedimiento de negociación de un acuerdo de pago. Serán aptos para acceder al mismo, en primer lugar, el empresario persona natural que se encuentre "[...] en situación de insolvencia con arreglo a lo establecido en el artículo 2 de esta Ley, o que prevea que no podrá cumplir regularmente con sus deberes" $\mathrm{y}$, siempre y cuando, su pasivo no supere los cinco millones de euros ${ }^{23}$. Se trata de dos requisitos que deben darse de forma acumulativa en el momento de instar la negociación extrajudicial ${ }^{24}$.

En cuanto a la insolvencia que señala este último precepto, alude simultáneamente a una situación de insolvencia por remisión a lo dispuesto en el artículo 2 -insolvencia actual- así como a "quien prevea que no podrá cumplir regularmente sus deberes" -insolvencia inminente-. Como consecuencia, a diferencia de la persona jurídica, tal y como entiende AZNAR GINER ${ }^{25}$, podrá instar el mecanismo el empresario persona natural insolvente, tanto de forma actual como inminente.

Olivencia Ruiz, M. (2015), “Concurso y preconcurso”, Revista de Derecho Concursal y Paraconcursal, núm. 22: p. 1.

21 Boldó RodA, C. (2015), “Capítulo XIV. El acuerdo extrajudicial de pagos. Aspectos procedimentales"..., op. cit., pp. 391 y 392.

${ }^{22}$ De acuerdo con el primer párrafo del artículo 231.1 LC: "El deudor persona natural que se encuentre en situación de insolvencia con arreglo a lo dispuesto en el artículo 2 de esta Ley, o que prevea que no podrá cumplir regularmente con sus obligaciones, podrá iniciar un procedimiento para alcanzar un acuerdo extrajudicial de pagos con sus acreedores, siempre que la estimación inicial del pasivo no supere los cinco millones de euros. En el caso de deudor persona natural empresario, deberá aportarse el correspondiente balance".

${ }^{23}$ Vid. artículo 231.1 LC, párrafo segundo. Este precepto prevé una definición de deudor persona física (o natural) a efectos concursales: "se considerarán empresarios personas naturales no solamente aquellos que tuvieran tal condición de acuerdo con la legislación mercantil, sino aquellos que ejerzan actividades profesionales o tengan aquella consideración a los efectos de la legislación de la Seguridad Social, así como los trabajadores autónomos".

${ }^{24}$ AZNAR GINER, E. (2013), Refinanciaciones de deuda, acuerdos extrajudiciales de pago y concurso de acreedores, Valencia: Tirant lo Blanch, p. 139.

${ }^{25}$ AZNAR GINER, E. (2013), Refinanciaciones de deuda, acuerdos extrajudiciales de pago y concurso de acreedores..., op . cit., p. 319. 
También puede acceder a la negociación cualquier persona jurídica, independientemente de que sea o no una sociedad de capital, siempre y cuando proceda los requisitos previstos en el artículo 231.2 LC. Al igual que sucede con la persona natural, el deudor persona jurídica deberá encontrarse en una situación de insolvencia que, en este caso, deberá ser actual, excluyéndose la inminente. Además, en caso de ser declaradas en concurso, el mismo no debería revestir especial complejidad y el deudor debe disponer de activos líquidos suficientes para satisfacer los gastos propios del acuerdo $^{26}$.

En lo concerniente a los acreedores, casi todos lo que tiene el deudor están invitados a la negociación del acuerdo, con las negativas consecuencias para su crédito en el caso de que se ausenten de la misma y, de esta forma, se podrán ver afectados por el contenido del acuerdo, es decir, por la quita y/o espera que se pacte entre las partes. No obstante, el artículo 231.5 LC prevé limitaciones en lo relativo a los créditos que pueden verse afectados. Este precepto excluye del procedimiento negociador a los acreedores públicos, que en ningún caso se podrán ver vinculados por el eventual acuerdo logrado entre el deudor y sus acreedores ${ }^{27}$.

Por otro lado, en atención al artículo 238 bis LC, los acreedores con garantía real, por la parte de su crédito que no exceda del valor de la garantía, únicamente quedarán vinculados por el acuerdo si hubiesen votado a favor del mismo. Así pues, los créditos dotados de garantía real sólo se verán afectados por el acuerdo extrajudicial si, de forma expresa, los acreedores titulares de los mismos lo comunican al mediador dentro del plazo de un mes contado desde que reciban la convocatoria a la que se refiere el artículo 234 LC. La exclusión del acreedor real "se antoja lógica",28, pues no tendría sentido imponerle una espera que no se le aplica en el concurso de acreedores.

\subsection{Procedimiento de consecución del acuerdo extrajudicial de pagos.}

De conformidad con el artículo 232.2 LC, el deudor que pretenda acogerse a este procedimiento deberá realizar una solicitud mediante formulario normalizado pidiendo la designación de un mediador concursal ${ }^{29}$. Por ende, la iniciativa no surge de las partes

\footnotetext{
${ }^{26}$ A contrario sensu, los supuestos en los que se excluye la posibilidad de acceder al acuerdo extrajudicial de pagos quedan reducidos básicamente a tres: uno, aquellos que fueran condenados en sentencia firme por delito contra el patrimonio, la orden socioeconómica, falsedad documental, contra la Hacienda Pública, la Seguridad Social o contra los derechos de los trabajadores en los diez años anteriores a la declaración de concurso; dos, las personas que, dentro de los cinco últimos años, se alcanzase un acuerdo extrajudicial de pagos con los acreedores, obtuvieran la homologación judicial de un acuerdo de refinanciación o fuesen declaradas en concurso de acreedores; y tres, quienes se encuentren negociando con sus acreedores un acuerdo de refinanciación o cuya solicitud de concurso fuese admitida a trámite.

${ }^{27}$ En concreto, este precepto dispone: "Los créditos con garantía real se verán afectados por el acuerdo extrajudicial conforme a lo dispuesto por los artículos 238 y 238 bis.

Los créditos de derecho público no podrán en ningún caso verse afectados por el acuerdo extrajudicial, aunque gocen de garantía real'.

${ }^{28}$ AZNAR GINER, E. (2013), Refinanciaciones de deuda, acuerdos extrajudiciales de pago y concurso de acreedores..., op. cit., p. 327.

${ }^{29}$ Para poder proceder a la apertura del concurso, la declaración del concursado, y para que esta declaración despliegue efectos, deben concurrir tres presupuestos esenciales: el presupuesto subjetivo, el presupuesto objetivo y el presupuesto formal. El primero de ello, atiende a la condición de persona del deudor, ya sea persona física o jurídica; el segundo, el presupuesto objetivo, se refiere a la necesaria
} 
en conflicto, sino que corresponde en exclusiva al deudor, pues no es necesario el consentimiento previo de los acreedores ni que los negocios de los que traen cuenta los créditos tuviesen previsto este medio de solución de conflictos ${ }^{30}$. Es este un punto donde el acuerdo extrajudicial se aparta de lo contemplado para la mediación en el artículo 16.1 LM, que requiere el común acuerdo de las partes, salvo que concurra un pacto de sometimiento a mediación ${ }^{31}$.

Por lo que respecta al órgano competente para recibir y resolver la solicitud, en el artículo 232.3 LC existe una dualidad en la posibilidad de dirigirse, en caso de que los deudores sean empresarios o entidades inscribibles, al Registrador Mercantil, o a un notario en los demás casos. Ahora bien, el RDL 1/2015 introduce como novedad la posibilidad para los deudores personas jurídicas o de persona natural empresario de acudir a las Cámaras Oficiales de Comercio, Industria, Servicios y Navegación que asumirán funciones de mediación y a la Cámara Oficial de Comercio, Industria, Servicios y Navegación de España. De la misma forma, la reciente normativa introduce un artículo 242 bis en la LC, en virtud del cual se determina que en el supuesto de acuerdo extrajudicial de pagos de personas naturales no empresarios, la competencia para su tramitación le corresponde a los notarios ${ }^{32}$.

Una vez admitida la solicitud, se procederá al nombramiento del mediador concursal. A este respecto, en virtud del artículo 233.1 LC, el órgano competente para conocer de la solicitud nombrará a la persona física o jurídica que "de forma secuencial corresponda" de entre las integradas en una lista oficial suministrada por el Registro de Mediadores e Instituciones de Mediación del Ministerio de Justicia ${ }^{33}$.

De acuerdo con esta idea, y a diferencia de lo que ocurre con los administradores concursales, por ejemplo, el nombramiento de los mediadores concursales no será discrecional. Tal y como prevé la Ley 14/2013, la designación será "secuencial", lo que implica simplemente un criterio temporal de antigüedad, de suerte que los mediadores ocuparán en la lista una secuencia coincidente con el orden de recepción de su

concurrencia del supuesto de la insolvencia, así el artículo 2.2 LC señala: "se encuentra en estado de insolvencia el deudor que no puede cumplir regularmente sus obligaciones exigibles"; y por último, el presupuesto formal es la declaración del concurso, que se produce mediante una declaración judicial, es decir, el auto declaratorio de concurso, sin el cual no existe declaración en concurso y, por tanto, no se producen los efectos que derivan de ella. BARROS MARUGÁN, M. I. (2015), "Los acuerdos extrajudiciales de pagos en la mediación concursal”, Tesis doctoral: pp. 9-13. [En línea] https://uvadoc.uva.es/bitstream/10324/18249/1/TFM-N.29.pdf.

${ }^{30}$ Gorriz LóPEZ, C. (2014), "Mediación concursal”, Diario La Ley, Sección Doctrina, núm. 8384, 24 de septiembre, Año XXXV: p. 5.

${ }^{31}$ Este punto es relevante puesto que rompe un principio esencial de la mediación: la voluntariedad.

${ }^{32}$ Es necesario destacar que esta atribución de competencia que, "acertadamente" se sustrae del Juzgado, es imperativa y indisponible para el deudor, de modo que una sociedad anónima, por ejemplo, no puede instar el nombramiento a un notario de su domicilio bajo pena de que esa solicitud sea inadmitida de plano por el fedatario en cuestión. AZNAR GINER, E. (2014), Mediación concursal: los acuerdos extrajudiciales de pago, Valencia: Tirant lo Blanch, p. 42.

${ }^{33}$ Esta lista debe garantizar que los inscritos cumplen las exigencias de la LM y, en particular, que tienen una formación específica para ejercer la mediación. Así, CASTILLEJO MANZANARES entiende que se les está exigiendo que "tenga formación acreditable no sólo en mediación, sino también en materia concursal". CASTILlejo MANZANARES, R. (2013), "La figura del mediador concursal en el "acuerdo extrajudicial de pagos”, Cuaderno Electrónico de Estudios Jurídicos, núm. 1, diciembre: pp. 19-36. 
formulario electrónico de solicitud, siendo el más antiguo el primero a nombrar, y así sucesivamente $^{34}$.

Una vez designado el mediador concursal, el registrador o notario deberá notificarle el nombramiento y éste aceptar el cargo. En buena lógica, si entendiese que incurre en alguna causa de incapacidad o incompatibilidad deberá ponerlo en conocimiento del "designante" para que éste, previa notificación a los interesados, proceda al nombramiento de un nuevo mediador concursal. Cuando el mediador acepte el cargo, el registrador o notario dará la oportuna publicidad al inicio del procedimiento de negociación de un acuerdo extrajudicial de pagos y a la designación del mediador concursal en los términos indicados en el artículo $233.3 \mathrm{LC}^{35}$.

Llegados a este punto, se daría comienzo al procedimiento de negociación propiamente dicho mediante la fase de negociación del acuerdo extrajudicial de pagos, que se presenta como una mediación, aun cuando son muchas las voces que entienden que no lo es, que nos encontramos ante una figura autónoma y distinta de la mediación, aunque fuertemente influenciada por la misma.

En este procedimiento, el mediador concursal tiene la labor de impulsar y controlar el desarrollo del mismo, así como de conciliar y buscar el acuerdo entre las partes, pero sin influenciarlas ni proponer solución de pago alguna. Ahora bien, según el artículo 234.1 LC, la primera actuación del mediador es la de proceder a comprobar la existencia y cuantía de los créditos y convocar al deudor y a los acreedores a una reunión ${ }^{36}$.

En cuanto a los efectos, la apertura del procedimiento le sirve al deudor de "escudo protector" ${ }^{37}$ frente a la actuación de los acreedores que pudiesen verse afectados por ese acuerdo. Y ello es así, puesto que los acreedores no podrán iniciar ni continuar ejecución alguna hasta un plazo máximo de tres meses, tal como señala el artículo 235.2 $\mathrm{LC}^{38}$. Asimismo, una vez inscrita la apertura en el Registro de la Propiedad o de Bienes Muebles, no será posible el acceso a los mismos de anotaciones preventivas de embargos o secuestros posteriores. Y, por último, los acreedores, desde la apertura, no podrán instar la declaración de concurso, en tanto no transcurran tres meses desde la comunicación. En consecuencia, el artículo 235.2.b) LC, parece introducir a los acreedores una advertencia consistente en el deber de "abstenerse de realizar acto alguno dirigido a mejorar la situación en que se encuentren respecto del deudor común".

\footnotetext{
${ }^{34}$ CASAnueva TOMÁs, J., "El desarrollo reglamentario de la figura del mediador concursal", p. 3. [En línea] http://www.mediacion.icav.es/archivos/contenido/816.pdf.

${ }^{35} \mathrm{El}$ registrador o notario "deberá comunicar de oficio la apertura de negociaciones al juez competente para la declaración de concurso", a fin de extender los efectos protectores del artículo 5 bis LC.

${ }^{36}$ En este punto, es preciso destacar que el apartado segundo del artículo 234 fue objeto de modificación por el RDL 1/2015, determinando que la convocatoria de la reunión se llevará a cabo por conducto notarial o cualquier medio de comunicación que garantice su recepción. Añade, además, que si constara la dirección electrónica de los acreedores, la comunicación deberá ser efectuada por esta vía.

${ }^{37}$ SeNÉs Motilla, C. (2014), "El acuerdo extrajudicial de pagos: ¿alternativa efectiva al concurso de acreedores?", Revista de Derecho Civil, vol. I, núm. 1, enero-marzo: p. 59.

${ }^{38}$ Se exceptúa la ejecución de la garantía real que podrá ser iniciada o continuada por el acreedor, en cuyo caso, no podrá participar en el acuerdo extrajudicial.
} 
De conformidad con el artículo 236.1 LC, una vez examinada la situación, el mediador debe hacer una propuesta de plan de pagos, que será remitida "tan pronto como sea posible" y será aprobada por los acreedores en la correspondiente reunión. Esta propuesta inicial comprende un plan de pagos de contenido preceptivo y un plan de viabilidad. Por lo que respecta a ese plan de pagos, si bien ha de ser enviado por el mediador con el consentimiento del deudor, la elaboración y el diseño corresponde al deudor, no al mediador concursal, que no puede intervenir en la adopción de su contenido $^{39}$. Por consiguiente, la tarea del mediador se circunscribe a ser el conducto de transmisión del plan, que "ni es suyo, ni lo vincula personalmente"

Dentro de los diez días naturales posteriores a que el mediador envíe la propuesta de acuerdo a los acreedores, según el artículo 236.3 LC, éstos podrán presentar propuestas alternativas o de modificación del plan de pagos formulado por el deudor. Transcurrido este plazo improrrogable, el mediador concursal remitirá a los acreedores el plan de pagos y viabilidad final aceptado por el deudor.

En la reunión para deliberar y debatir sobre la propuesta de ese plan, los acreedores asistentes se manifestarán a favor o en contra de la mencionada propuesta o se abstendrán. En el supuesto de que el acuerdo sea aceptado, la eficacia del mismo requiere de su formalización en escritura pública, que servirá para la conclusión del expediente ${ }^{41}$. A contrario sensu, si el acuerdo no fuese alcanzado y el deudor continuara incurso en situación de insolvencia, el mediador se verá forzado a instar el concurso consecutivo dada la imposibilidad de lograr un acuerdo extrajudicial de pagos, actuación que tendrá que seguir también en el supuesto de que el acuerdo obtenido fuese incumplido o anulado, tal como prevé el artículo 242 LC.

Ahora bien, este acuerdo se podrá impugnar por los motivos tasados del artículo 239.2 $\mathrm{LC}^{42}$, ante el juzgado que fuese competente para conocer del concurso del deudor, sin

\footnotetext{
${ }^{39}$ En la línea de intentar potenciar el procedimiento y favorecer su éxito, la actual regulación -introducida por el RDL 1/2015- ofrece un mayor margen de actuación al mediador concursal, pues amplía y "liberaliza" el posible contenido del acuerdo extrajudicial de pagos. PUlgar EzQUERRA, J. (2015), “Acuerdos extrajudiciales de pagos, PYMES y mecanismos de segunda oportunidad”..., op. cit., p. 9. Éste puede consistir en una espera de incluso diez años, aumentándose así el plazo frente a los tres de la regulación anterior, o en una quita que, mientras que antes no podía superar el 25 por ciento del importe de los créditos afectados, se permite ahora sin ningún tipo de límite.

${ }^{40}$ AZNAR GINER, E. (2013), Refinanciaciones de deuda, acuerdos extrajudiciales de pago y concurso de acreedores..., op. cit., p. 335.

${ }^{41}$ Los efectos de la obtención de un acuerdo son muy similares a los del convenio concursal. Así, en el supuesto de que se apruebe y no sea impugnado o una vez verificada la impugnación ésta sea desestimada, surgen una serie de consecuencias para los acreedores, previstas en el artículo 240 LC.

No será preciso que la escritura pública deba otorgarse ante el notario que designó al mediador concursal. Si fuera distinto, se entiende que deberá comunicarlo a éste para su debida constancia en el expediente y cierre del mismo. Para otorgarse la escritura, ha de exhibirse al fedatario público el original del acta de la reunión en la que se adoptó el acuerdo de pago y se incorporará a la escritura testimonio de la misma. BOLDó RODA, C. (2015), "Capítulo XIV. El acuerdo extrajudicial de pagos. Aspectos procedimentales"..., op. cit., p. 424.

${ }^{42}$ De acuerdo con el apartado 1 de este precepto, la legitimación activa le corresponde al "acreedor que no hubiera sido convocado o no hubiera votado a favor del acuerdo o hubiera manifestado con anterioridad su oposición en los términos establecidos en el artículo 237.1 [...]”. Además, en el segundo apartado se señala que "La impugnación no suspenderá la ejecución del acuerdo y solo podrá fundarse en la falta de concurrencia de las mayorías exigidas para la adopción del acuerdo teniendo en cuenta, en
} 
necesidad de que se suspenda la ejecución del acuerdo. La resolución que resuelva sobre la impugnación del acuerdo revestirá la forma de sentencia y producirá efectos de cosa juzgada, pudiendo ser recurrida en apelación.

Por último, el acuerdo extrajudicial de pagos no pone fin al procedimiento ni libera al mediador concursal de sus obligaciones, pues únicamente cuando éste tenga lugar "de forma íntegra" ${ }^{43}$ podrá poner fin a su actividad. Para ello, tendrá que hacerlo constar en un acta notarial que será publicada en el BOE y en el Registro Público Concursal ${ }^{44}$.

\section{Conclusión.}

A nuestro juicio, de todo cuanto se ha señalado cabe inferir que el modelo que se está construyendo con respecto a los acuerdos extrajudiciales de pagos es susceptible de ser cuestionado. Y es que, a decir verdad, el régimen instaurado para la mediación concursal por la Ley 14/2013 presenta importantes diferencias en relación al régimen general del procedimiento mediador. Nótense para ilustrar la señalada afirmación: la legitimación para el inicio de las negociaciones, el procedimiento de designación del mediador concursal, el sistema remuneratorio implantado, etc. Así pues, no son pocos los ejemplos en los que queda patente la colisión con algunos de los principios informadores básicos del método alternativo de resolución de conflictos que ahora nos ocupa.

Ahora bien, a pesar de haber negado que el acuerdo extrajudicial de pagos sea, en puridad, una mediación, se puede defender su calificación como tal desde una perspectiva lato sensu. Cierto es que la mediación concursal, en el ámbito del preconcurso, es una mediación especial, pero fundamentalmente persigue el mismo objetivo que cualquier otra: alcanzar un pacto negociado que evite el concurso de acreedores. Persigue, en otras palabras, un acuerdo extrajudicial de pagos que no sólo resuelva con mayor celeridad la situación de insolvencia en la que se encuentra el deudor, sino que mantenga la paridad entre un grupo plural de acreedores y desjudicialice esos procesos de insolvencia, con todo lo que ello comporta en materia de desobstrucción de nuestros órganos jurisdiccionales.

\section{Bibliografía.}

- AgÜERo ORTIZ, A. (2013), "El mediador concursal como administrador extraconcursal", Revista de Derecho Concursal y Paraconcursal, núm. 20, Editorial La Ley, Sección Varia, segundo semestre.

\footnotetext{
su caso, a los acreedores que, debiendo concurrir, no hubieran sido convocados, en la superación de los límites establecidos por el artículo 236.1 o en la desproporción de las medidas acordadas".

${ }^{43}$ Gorriz LóPEZ, C. (2014), "Mediación concursal"..., op cit., p. 9.

${ }^{44}$ La referida publicación del acuerdo extrajudicial de pagos se llevará a cabo a través de anuncio remitido por el registrador mercantil o el notario. De conformidad con el artículo 14 RD 892/2013, de 15 de noviembre, por el que se regula el Registro Público Concursal, este anuncio contendrá: los datos identificativos del deudor, incluyendo su número de identificación fiscal; el Notario o Registrador competente; el número de expediente de nombramiento del mediador; el nombre del mediador concursal, incluyendo su número de identificación fiscal; y la indicación de que el expediente está a disposición de los acreedores interesados en el Registro Mercantil o Notaría correspondiente para la publicidad de su contenido.
} 
- AzNAR Giner, E. (2013), Refinanciaciones de deuda, acuerdos extrajudiciales de pago y concurso de acreedores, Valencia: Tirant lo Blanch.

- AZnAR Giner, E. (2014), Mediación concursal: los acuerdos extrajudiciales de pago, Valencia: Tirant lo Blanch.

- BARONa Vilar, S. (2013), Mediación en asuntos civiles y mercantiles en España. Tras la aprobación de la Ley 5/2012, de 6 de julio, Valencia: Tirant lo Blanch.

- Barros Marugán, M. I. (2015), "Los acuerdos extrajudiciales de pagos en la mediación concursal", Tesis doctoral. [En línea] https:/uvadoc.uva.es/ bitstream/10324/18249/1/TFM-N.29.pdf.

- Boldó RodA, C. (2015), "Capítulo XIV. El acuerdo extrajudicial de pagos. Aspectos procedimentales”, en Boldó RodA, C. (Dir.) y ANDREU MARTí, M. M. (Coord.): La mediación en asuntos mercantiles, Valencia: Tirant lo Blanch.

- Casanueva Tomás, J., "El desarrollo reglamentario de la figura del mediador concursal". [En línea] http://www.mediacion.icav.es/archivos/contenido/816.pdf.

- Castillejo Manzanares, R. (2013), Comentarios a la Ley 5/2012, de mediación en asuntos civiles y mercantiles, Valencia: Tirant lo Blanch.

- Castillejo Manzanares, R. (2013), "La figura del mediador concursal en el "acuerdo extrajudicial de pagos", Cuaderno Electrónico de Estudios Jurídicos, núm. 1, diciembre: pp. 19-36.

- Castillejo Manzanares. R. (2017), "La mediación”, en Castillejo Manzanares, R. (Dir.), Noya Ferreiro, L. y Rodríguez Álvarez, A. (Coords.): Tratado sobre la disposición del proceso civil, Valencia: Tirant lo Blanch.

- Gómez Segade, J. A. (2011), "Reflexión sobre la crisis económica y el derecho mercantil (referencia a los acuerdos de refinanciación en el concurso)", en Piloñeta Alonso, L. M. e Iribarren Blanco, M. (Coords.): Estudios de derecho mercantil en homenaje al profesor José María Muñoz Planas, Cizur Menor (Navarra): Civitas Thomson.

- Gorriz LóPez, C. (2014), "Mediación concursal”, Diario La Ley, Sección Doctrina, núm. 8384, 24 de septiembre, Año XXXV.

- LASHERAS, P. (2014), “Es mediador el mediador concursal?”, Actualidad Jurídica Aranzadi, núm. 895, Editorial Aranzadi, Madrid.

- Martín MolinA, P. B. (2015), "La segunda oportunidad para la persona natural, el autónomo y la pequeña empresa en el ámbito de la insolvencia”, Diario La Ley, Sección Doctrina, núm. 8531, 4 de mayo, Ref. D-172. 
- Merino EspinAR, M. B. (2015), "Una primera aproximación a la realidad del acuerdo extrajudicial de pagos y la figura del mediador concursal y su relación con el Registro de la Propiedad", Revista de Derecho Civil, vol. II, núm. 1, eneromarzo.

- Olivencia Ruiz, M. (2015), "Concurso y preconcurso", Revista de Derecho Concursal y Paraconcursal, núm. 22.

- PAstor Seller, E. (2013), "La mediación como herramienta de intervención social”, en Gorjón Gómez, F. y López Pelázez, A. (Coord.): Estado del arte de la mediación, Cizur Menor (Navarra): Editorial Aranzadi.

- Pulgar EzQuerra, J. (2013), "Ley de emprendedores y segunda oportunidad”, El Notario del Siglo XXI, Opinión, núm. 51, septiembre-octubre. [En línea] http://www.elnotario.es/index.php/opinion/opinion/3517-ley-de-emprendedoresy-segunda-oportunidad.

- Pulgar EzQuerra, J. (2015), “Acuerdos extrajudiciales de pagos, PYMES y mecanismos de segunda oportunidad", Diario La Ley, Sección Doctrina, núm. 8538, 13 de mayo, Ref. D-188.

- QuiJano GonZÁlez, J., "Las sucesivas reformas de la Ley Concursal española en materia de preconcursalidad". [En línea] http://cuadernosdederechopara ingenieros.com/articulo/el-acuerdo-extrajudicial-de-pagos/.

- RoJo FERnÁNDEZ-Rio, A. (2003), "La reforma del derecho concursal español", en ROJO FERNÁNDEZ-RIO, A. (Dir.): La reforma de la legislación concursal, MadridBarcelona: Marcial Pons.

- Senés Motilla, C. (2014), "El acuerdo extrajudicial de pagos: ¿alternativa efectiva al concurso de acreedores?", Revista de Derecho Civil, vol. I, núm. 1, enero-marzo.

- VAliÑo Ces, A. (2017), "La sesión informativa en la mediación intrajudicial ¿voluntaria u obligatoria?", en CAstillejo Manzanares, R. (Dir.), Alonso SAlGADO, C. y VAliÑo CES, A. (Coords.): La mediación a examen: experiencias innovadoras y pluralidad de enfoques, Santiago de Compostela: Servicio de Publicaciones e Intercambio Científico. 